\title{
Todo mundo é igual? Construções de gênero sob o olhar da juventude
}

\author{
Is everyone the same? Gender constructions under the eyes of youth
}

\section{¿Todo el mundo es igual? Construcciones de género bajo la mirada de la juventud}

\author{
Caroline Gonçalves Nascimento ${ }^{1}$ \\ Millena Holz Waskow ${ }^{2}$ \\ Marlene Neves Strey ${ }^{3}$ \\ Ângelo Brandelli Costa ${ }^{1}$
}

Recebido em 01/06/2019; revisado e aprovado em 13/01/2020; aceito em 04/02/2020

DOI: http://dx.doi.org/10.20435/inter.v22i1.2597

\begin{abstract}
Resumo: A escola pode revelar, entre outras coisas, situações e procedimentos pedagógicos e curriculares relacionados à produção de diferenças e distinções sociais que interfiram na formação e na produção social do desempenho escolar. A Educação de Jovens e Adultos é um sistema de ensino da rede pública no Brasil que oportuniza àqueles que não tiveram acesso à escola quando ainda eram crianças, seja qual for o motivo, que se alfabetizem, obtendo assim o que é um direito à cidadania. O presente artigo é resultado de uma investigação que objetivou analisar construções de gênero na juventude a partir das percepções de alunas(os) da modalidade de ensino Educação de Jovens e Adultos. Foram expostas publicações da rede social Facebook, com a temática "gênero", a estudantes com idades entre 15 e 29 anos de uma escola municipal da região metropolitana do Rio Grande do Sul. Para tanto, foram organizados cinco grupos focais, nos quais se buscou analisar as construções sociais de gênero, na perspectiva das(dos) jovens, a partir do método da análise temática. Os principais resultados revelam como as construções de gênero apresentam-se de forma plural para as(os) jovens na sociedade atual, até mesmo em função de terem vivências diferentes de vida.
\end{abstract} Palavras-chave: gênero; juventude; escola.

Abstract: The school can reveal, among other things, pedagogical and curricular situations and procedures related to the production of social differences and distinctions, which interfere in the formation and social production of the school performance. Youth and Adult Education is a public school education system in Brazil that provides opportunities for those who did not have access to school when they were still children, for whatever reason, to become literate, thus obtaining what is a right to citizenship. This article is the result of an investigation that aimed to analyze the constructions of gender in the youth from the perceptions of students of the modality of education Youth and Adult Education. Publications of the social network Facebook, with the theme "Gender", were exposed to students between 15 and 29 years of a municipal school in the metropolitan region of Rio Grande do Sul. We carried out five focus groups in order to analyze the social constructions of gender from the young people's perspective, from the thematic analysis method. The main results reveal how gender constructions present themselves in a plural form for young people in today's society, even as they have different life experiences.

Keywords: gender; youth; school.

Resumen: La escuela puede revelar, entre otras cosas, situaciones y procedimientos pedagógicos y curriculares relacionados a la producción de diferencias y distinciones sociales que interfieren en la formación y en la producción social del desempeño escolar. La Educación de Jóvenes y Adultos es un sistema de educación escolar pública en Brasil que ofrece oportunidades para aquellos que no tenían acceso a la escuela cuando aún eran niños, por cualquier razón, para alfabetizarse, obteniendo así el derecho a la ciudadanía. El presente artículo es el resultado de una investigación que objetivó analizar construcciones de género en la juventud a partir de las percepciones de alumnos de la modalidad de enseñanza Educación de Jóvenes y Adultos. Se expuso publicaciones de la red social Facebook, con la temática "Género", a estudiantes entre 15 y 29 años de una escuela municipal de la región metropolitana de Rio Grande do Sul. Para ello, se realizaron cinco grupos focales, donde se buscó analizar las construcciones sociales de género en la perspectiva de los jóvenes, a partir del método del análisis temático. Los principales resultados revelan cómo las construcciones de género se presentan de forma plural para los jóvenes en la sociedad actual, incluso en función de tener vivencias diferentes de vida.

Palabras claves: género; juventud; escuela.

\footnotetext{
${ }^{1}$ Pontifícia Universidade Católica do Rio Grande do Sul (PUCRS), Porto Alegre, Rio Grande do Sul, Brasil.

${ }^{2}$ Universidade Federal de Ciências da Saúde de Porto Alegre (UFCSPA), Porto Alegre, Rio Grande do Sul, Brasil.

${ }^{3}$ Universidade Feevale, Novo Hamburgo, Rio Grande do Sul, Brasil.
} 


\section{INTRODUÇÃO}

As juventudes atuais vivenciam mudanças que podem transformar ou não alguns lugares e papéis ocupados no decorrer de suas vidas. De acordo com Nunes e Weller (2014), destacam-se as mudanças no mundo da família e do trabalho, bem como seus impactos em diferentes dimensões da vida individual e social. A juventude, porém, vai além de um fenômeno de mudanças físicas, sendo atravessada por questões mais abrangentes de ordem social, cultural e histórica (PIZZINATO et al., 2017). Os estímulos cotidianos sobre as(os) jovens produzem diversas visões de mundo e ideologias; portanto, cada gesto aparentemente comum está carregado de significados e de estímulos diversos (NUNES; WELLER, 2014). Desse modo, o estímulo utilizado no presente estudo para tencionar a discussão foi o Facebook, criado em 2004 por Mark Zuckerberg e, desde então, considerado como a rede social mais utilizada entre as pessoas (ASSUNÇÃO; MATOS, 2014). Essa rede pode, com seu conteúdo, contribuir nas construções de gênero e no modo como homens e mulheres situam-se no mundo, na cultura e nas sociedades.

A concepção de gênero é adotada no estudo como categoria de análise que se refere às relações de poder existentes entre mulheres e homens, e é usada pelo feminismo para se problematizar "construções culturais" de ideias acerca dos papéis adequados aos homens e às mulheres (SCOTT, 1995). Pode-se dizer que as construções de gênero produzidas pela juventude podem, ou não, estar associadas aos modelos hegemônicos ainda naturalizados pela sociedade e que, por vezes, alimentam a dominação masculina. A escola, que deveria ser reconhecida como um espaço de formação acadêmica e de humanização, livre de qualquer tipo de preconceito, tem sido um espaço de reprodução desses modelos hegemônicos. Bento (2011) refere que um dos meios para que espaços educativos não reproduzam comportamentos de gênero é ampliar o olhar para a forma como a sociedade produz as verdades a respeito do que deve ser reproduzido. Para que seja possível a desconstrução da produção e da reprodução de verdades por parte da sociedade, o primeiro passo seria subverter os pressupostos de neutralidade instaurados durante tanto tempo nos espaços escolares (MISKOLCI, 2012).

A escola pode revelar, entre outras coisas, situações e procedimentos pedagógicos e curriculares relacionados à produção de diferenças e distinções sociais que interfiram na formação e na produção social do desempenho escolar (JUNQUEIRA, 2013). É notório o desafio que a Educação enfrenta no sentido de repensar algumas de suas principais ações. Miskolci (2012) sugere que as(os) educadoras(es) deveriam questionar-se sobre o que significa educar e como se faz isso, pois, em uma lógica não normalizadora, educar seria uma atividade dialógica em que os aspectos invisibilizados deveriam fazer parte do cotidiano escolar das(os) estudantes.

As autoras Rizza, Ribeiro e Mota (2018) atentam para o fato de que se viveu um momento histórico no qual a promoção e o reconhecimento da diversidade e da diferença entraram na ordem do discurso. Porém, por mais que isso tenha acontecido, a possibilidade de um retrocesso torna-se maior, principalmente quando se começa a falar de "ideologia de gênero", uma expressão de conotação predominantemente negativa em nosso país, conotação essa adotada por grupos conservadores que condenam qualquer diálogo acerca das questões de gênero e sexualidade em espaços educacionais (SEFFNER, 2016). A escola nada mais é do que um espaço de formação humana, no qual se torna fundamental que haja discussões acerca das compreensões de gênero, sexualidade e diversidade sexual; para que exista um processo de humanização, é essencial que se rompam algumas ideias cristalizadas pela sociedade (CAMPOS, 2015). Quando o processo 
de humanização das discussões for alcançado, uma juventude consciente das relações sociais a que estão submetidas no universo das diversidades estará formada.

A Educação de Jovens e Adultos é um sistema de ensino da rede pública no Brasil que oportuniza àqueles que não tiveram acesso à escola quando ainda eram crianças, seja qual for o motivo, que se alfabetizem, obtendo assim o que é um direito à cidadania (RAFAELI, 2015). Considerando a importância da Educação para a possibilidade de transformações sociais na sociedade atual, faz-se necessário que as(os) educadoras(es) de hoje tenham maiores conhecimentos para trabalhar com as(os) jovens e adultas(os) da atualidade, não só utilizando didáticas diferentes, levando em conta a tecnologia que está presente no cotidiano das pessoas, mas também sabendo lidar com as diferenças e as individualidades das(os) alunas(os).

A inserção da Internet no cotidiano da maioria das pessoas e a influência das mídias sociais têm se tornado assuntos recorrentes, causando impacto na cultura e na forma de expressão, bem como nas questões de gênero, também expostas e continuamente construídas num espaço virtual. O contexto apresentado propicia a possibilidade de se problematizar as relações sociais construídas e aceitas socialmente e culturalmente (BERNARDES, 2014). A Internet, portanto, acaba tornando-se um espaço múltiplo de comunicação. Os espaços virtuais são considerados por Pierre Lévy (1999) como modos de existência e surgimento tanto da verdade quanto da mentira, sendo vistos também como espaços que ainda dependem de um suporte físico, mas não de uma visão de tempo e espaço tradicional.

Diante da importância de se discutir tais temáticas, tendo em vista a participação que a mídia tem na produção e na reprodução de subjetividades, representando muitas vezes a única ou a principal fonte de informação e de formação de opinião da sociedade, e considerandose também a resistência e a dificuldade encontradas nos espaços escolares para se discutir "gênero", este estudo tem o objetivo de analisar as diferentes percepções de gênero construídas e vivenciadas por jovens no cotidiano de suas vidas, a partir da exposição de publicações da rede social Facebook, com a temática "gênero", a estudantes com idades entre 15 e 29 anos, matriculados na modalidade de ensino Educação de Jovens e Adultos (EJA).

\section{METODOLOGIA}

O artigo Todo mundo é igual? Construções de Gênero sob o olhar da Juventude é um recorte de uma pesquisa de mestrado que tem como foco as redes sociais e é situado em uma perspectiva que busca, em seus referenciais teóricos, uma relação entre a juventude e as questões de gênero vivenciadas por jovens no cotidiano de suas vidas. Assim, mais do que estabelecer um método de pesquisa, delimitou-se uma perspectiva teórico-metodológica com base em princípios que nos conduzem a diferentes compreensões do campo de pesquisa. Foram analisadas as construções de gênero a partir das experiências trazidas pelas(os) jovens acerca dessa temática, as quais estão presentes nos diferentes espaços que ocupam na sociedade.

Torna-se fundamental entender como as(os) jovens se reconhecem nos grupos em que estão inseridas(os), bem como quais são os questionamentos, os discursos e as angústias presentes em seus discursos e que norteiam o modo como a discussão acontece. Saber como se dão as diferentes percepções de cada uma(um), por meio dos debates tensionados a partir da apresentação de publicações da rede social Facebook, com a temática "gênero", revela o quanto as questões de gênero presentes nos discursos estão relacionadas às vivências diárias dessas(es) 
jovens. Também é importante mencionar o quanto a escola pode ser um local acolhedor e estimulante para se promover essas discussões.

O estudo foi realizado em uma escola municipal da região metropolitana do Rio Grande do Sul, com jovens com idades entre 15 e 29 anos matriculadas(os) em séries que compõem o Ensino Fundamental. Buscou-se estabelecer contato com jovens usuárias(os) da referida rede social, os quais demonstraram interesse em participar do estudo por meio de uma ficha demográfica. Para tanto, foram entregues dois Termos de Consentimento Livre e Esclarecido, um dirigido às(aos) jovens maiores de 18 anos e outro às(aos) responsáveis das(dos) jovens menores de 18 anos, que também assinaram um Termo de Assentimento para participar da pesquisa.

As(os) participantes selecionadas(os) para o estudo foram jovens do Ensino Fundamental, matriculadas(os) na modalidade de ensino Educação de Jovens e Adultos (EJA), que é o modelo de ensino correspondente ao antigo supletivo. A EJA é direcionada para pessoas que não concluíram o Ensino Fundamental (1ํgrau) ou o Ensino Médio (2ograu) na idade própria (PORTAL EDUCAÇÃO, 2017). Os critérios de inclusão utilizados foram: 1) as(os) jovens estarem entre 15 e 29 anos, pois, por mais que a modalidade de ensino não limite um período de idade, o trabalho focou no período determinado pelo Estatuto da Juventude (Lei n. 12.852/2013); 2) as(os) jovens estarem matriculadas(os) na escola escolhida; e, por fim, 3) as(os) jovens serem membros da rede social Facebook.

Utilizou-se a metodologia dos grupos focais, a qual, conforme Barbour (2009), caracteriza-se por qualquer discussão em que a(o) pesquisadora(or) esteja ativamente atenta(o), encorajando as interações do grupo. Por meio de tais grupos, foram observados conceitos como opiniões, sentimentos, explicações, valores e crenças, expressos por linguagem, atitudes e condutas das(os) participantes. A escolha pelo método do grupo focal se deu porque o instrumento de coleta de dados proporciona um importante recurso de interação grupal que tem o papel de produzir e ampliar problematizações relativas a um tema ou foco específico (BACKES et al., 2011). $O$ instrumento permite que se conheça a percepção das(os) jovens e os modos pelos quais as perspectivas delas(eles) são socialmente construídas. Os grupos focais tinham no mínimo oito e no máximo dez participantes, as(os) quais foram convidadas(os) e encorajadas(os) a discutirem o tema de pesquisa em questão nas suas mais diversificadas dimensões, dentro de um processo de interação e participação das(os) envolvidas(os) (GASKELL, 2002).

Foram expostas nos grupos focais publicações de páginas diversas do Facebook com a temática "gênero". O critério de seleção das publicações foi por conveniência, e a duração dos grupos variou de 40 minutos até uma hora. Os áudios resultantes desses grupos foram transcritos para posteriormente serem analisados.

Para analisar os dados, foi utilizado o método da análise temática dos temas que emergiram (BRAUN; CLARKE, 2006). O processo de análise e interpretação do material, de acordo com o método da análise temática, propõe seis fases, sendo elas: familiarização com os dados, codificação, busca pelos temas, revisão dos temas, definição e nomeação dos temas e relatório/análise final.

A seguir, serão apresentados os temas constituídos a partir da análise temática de Braun e Clarke (2006). Os dados significativos oriundos dos grupos focais, apresentados a partir das percepções de jovens estudantes da EJA - identificadas(os) durante as análises com nomes fictícios, para fins de manter o seu anonimato -, serão agrupados nos seguintes temas: percepções sobre movimentos sociais e igualdade de gênero; e papéis de gênero na sociedade. 


\section{RESULTADOS E DISCUSSÃO}

\subsection{Percepções sobre movimentos sociais e igualdade de gênero}

Os movimentos sociais e as discussões sobre igualdade de gênero estão cada vez mais presentes na sociedade, principalmente entre as(os) jovens. Como consequência, os debates sobre essas temáticas aparecem com frequência nas falas das(os) alunas(os), as(os) quais apresentam as mais distintas percepções sobre o tema.

Quando as(os) entrevistadas(os) foram questionadas(os) sobre o feminismo, em um mesmo grupo foram expostas diferentes percepções, principalmente em relação ao movimento feminista. Por mais que existam afirmações de apoio ao movimento, houve também discursos que evidenciam a falta de informação ao respeito do assunto. Nos trechos abaixo, um grupo de homens faz comentários sobre o feminismo, demonstrando a importância do movimento para o meio social, discutindo sob um viés positivo a relevância do movimento.

Tipo, algumas leis são em favorecimento aos homens e não às mulheres. Acho que o feminismo tem a ver com isso, pois isso precisa ser mudado. (Cristiano, 17 anos, $6^{\circ}$ ano $)^{4}$.

Tem homens que trabalham e desempenham a mesma função que a mulher e ganham mais que ela, não tem cabimento isso aí. Por que a mulher não pode ganhar o mesmo salário se está fazendo a mesma coisa? (Douglas, 16 anos, $6^{\circ}$ ano).

Tá muito errado isso, não deveria existir essa desigualdade. Acho que o feminismo é muito importante para que se acabe com essas diferenças sem sentido. (Milton, 20 anos, $8^{\circ}$ ano).

Entretanto, durante a execução dos grupos, opiniões errôneas a respeito do feminismo e da igualdade de gênero foram encontradas. Houve um debate complexo em torno do feminismo, e alguns relatos femininos revelaram-se mais preconceituosos e conservadores que os dos homens, os quais por vezes acabam produzindo um discurso mais desnaturalizado sobre o movimento. Muitas dessas construções, entretanto, podem ser relacionadas ao que é veiculado na mídia, pois conteúdos não condizentes com a proposta do movimento feminista, propagados por indivíduos que ainda perpetuam o modelo normalizado de mulher mãe/dona de casa, são cada dia mais difundidos por inúmeros meios de comunicação, especialmente as mídias sociais (COELHO, 2016).

Sou contra! (Ricardo, 17 anos, $6^{\circ}$ ano).

Sou a favor! (Milton, 20 anos, $8^{\circ}$ ano).

Contra o machismo também... (Raíssa, 26 anos, $7^{\circ}$ ano).

É, contra o machismo também... Mas é sem noção esse feminismo aí! Tá louco! (Jairo, 15 anos, $8^{\circ}$ ano).

Embora não haja consenso quanto à ampliação das críticas feministas para além do universo "feminino", assim como propõe a teoria queer, nem quanto à inclusão de homens no movimento, é impossível pensar em uma sociedade na qual todos, sem exceção, possam trabalhar juntos pelo combate ao machismo e a tantos preconceitos que nos aprisionam, cerceiam-nos e nos subjugam. A importância de dispositivos midiáticos na comunicação e na divulgação de ideias feministas pode ser observada ainda hoje, por meio do desenvolvimento recente de uma ampla gama de mídias alternativas por grupos feministas (WOITOWICZ, 2012).

\footnotetext{
${ }^{4}$ As falas dos participantes foram transcritas respeitando-se a originalidade do discurso oral, e por isso podem conter incorreções relativas à norma culta da língua portuguesa.
} 
O feminismo, mesmo com todos os avanços, ainda gera incômodo, tanto para os opressores quanto para os oprimidos, visto que remete à desconstrução de concepções em uma sociedade que se debruça sobre ideologias de dominação entre gêneros para que possam ser mantidas as concepções históricas de construções realizadas acerca do homem e da mulher. Essa mesma ideologia separa as mulheres, podendo enfraquecê-las e gerando conflitos internos tanto nos próprios feminismos quanto dentro do gênero feminino construído, sendo que essas concepções perpassam por diversas esferas durante a vida (COELHO, 2016).

O feminismo luta pelos direitos das mulheres, e não pelos direitos iguais. Só serve para as mulheres terem os direitos delas. (Kátia, 17 anos, $9^{\circ}$ ano).

Elas ficam falando que a culpa é dos homi e não sei o quê, porque não podia votar antes e agora pode, e elas quer eleger tudo é mulher... se escolher uma presidente, tem que ser mulher. (Alex, 16 anos, $9^{\circ}$ ano).

As construções realizadas ao longo dos séculos a respeito dos gêneros perpassam por comportamentos humanos em diversas esferas do meio social, inclusive por indivíduos que sofrem com a estagnação e o preconceito gerados pela reprodução desses estereótipos. Incluem-se aqui as mulheres que reproduziram os conteúdos de teor machista durante a realização dos grupos. Por meio da propagação desses pensamentos enviesados, a probabilidade de enfraquecimento dos próprios movimentos feministas é existente; contudo, isso demonstra o quanto as mulheres também expressam as estruturas da pressão, as quais ainda estão fixadas a essa lógica pautada em ideologias e construções distorcidas a respeito de gênero.

No que tange ao grupo focal feminino, em seus relatos são exemplificadas as desigualdades de gênero e as suas percepções sobre os movimentos sociais, principalmente os feministas. As diferentes compreensões acerca desses dois fatores são apresentadas e debatidas nesse grupo. São trazidas à tona algumas de suas vivências diárias e as implicações da construção do ser mulher no ambiente escolar e na sociedade em que estão inseridas.

É, tem preconceito aqui... A gente não pode usar decote e não pode vir com um calção muito curto, porque os meninos não vão respeitar a gente, eles têm que aprender a respeitar a gente independente da roupa que a gente tiver. Que nem a gente vem de decote e os guris falam: 'Ah, tão se oferecendo! Vou botar no prato porque dá pra comer'. Mas é o jeito de se vestir, eles têm que entender isso e respeitar isso. (Raíssa, 26 anos, $7^{\circ}$ ano).

Eu também namorava, mas numa festa uma vez eu tava dançando com as minhas amigas e ele me puxou... a minha irmã tava junto... ele me puxou e disse que eu tava me oferecendo para aqueles caras, ele me chamava de puta e criticava o jeito como eu me vestia também. Eu acho que mulher tem que se vestir do jeito que ela quiser. Eu me visto pra me sentir bem. (Patrícia, 18 anos, $7^{\circ}$ ano).

No entanto, no discurso das alunas, as construções do gênero feminino apresentadas em suas vivências escolares são trazidas por meio da estereotipagem e do preconceito no tocante às suas vestimentas. Roupas decotadas e shorts curtos, por exemplo, são referidos como sendo uma "vulgaridade feminina" por parte da sociedade machista. Por meio da reprodução desse pensamento, as alunas foram criticadas e até mesmo objetificadas, como relatado por uma das estudantes, a qual verbalizou ter sido desrespeitada por um de seus colegas. Os comentários apresentados acima demonstram a desigualdade de gênero e os estigmas sociais relacionados às construções acerca da imagem de mulher "ideal". Assim como apresentado por Thompson (2007), tal desigualdade e a normalização desse tipo de comportamento são estratégias ideológicas de dominação realizadas 
pela maioria, aqui estabelecida como sendo composta por homens heterossexuais.

Mulher perfeita é aquela que ajuda em tudo, independente se bebe ou não. (Laércio, 17 anos, $9^{\circ}$ ano).

Sempre rola esses comentários, mulher não pode beber, mulher pra casar não pode fazer isso e aquilo, acho tudo isso uma bobagem. Tem mulher que bebe mais que homem, né gurias? (Raíssa, 26 anos, $7^{\circ}$ ano).

Mulher perfeita não existe! Existe uma quase! A mulher perfeita acompanha o cara em festa, por exemplo, porque senão vaificar um troço estranho. Tipo... o cara quer jogar bola, a mina tem que acompanhar o cara. Se a mina quer ir no shopping, o cara tem que acompanhar a mina também. (Guilherme, 16 anos, $7^{\circ}$ ano).

O desejo e a vontade femininos são muito mais complexos do que o simples ato de exercer o livre-arbítrio, já que a interferência promovida pelo meio social nas questões do público feminino, envolvendo seus comportamentos, aparenta ser mais governada por normas de conduta do que os quando ocorre com outros gêneros. Tal fato se relaciona diretamente com os papéis impostos aos gêneros, o que será discutido especificamente no próximo tema de análise. A separação de direitos e possibilidades de comportamento atribuídos aos homens e às mulheres no meio social permeia diversos ambientes sociais. Além dos preconceitos e das desigualdades relatados pelas participantes dos grupos dentro da sala de aula, festas e locais de lazer também são alvo de repressão, como realçado na fala do grupo abaixo:

Eu só acho errado nas festas que a mulher paga meio e o homem tem que pagar inteiro. (Marcos, 15 anos, $6^{\circ}$ ano).

Pra ter bastante mulher pros cara escolher. (Cristiano, 17 anos, $6^{\circ}$ ano).

É uma vitrine de mulher, né, sora?. (Wilmar, 16 anos, $7^{\circ}$ ano).

Pra entrar mais mulher e ficar bêbada. (Flávio, 16 anos, $7^{\circ}$ ano).

A partir do que foi exposto acima, podemos fazer a análise de três fatores interligados que permearam o discurso das(os) participantes. O primeiro diz respeito ao valor dos ingressos nas festas, ambiente no qual comumente aqueles vendidos às mulheres são mais baratos ou até mesmo de graça, enquanto para os homens custam mais caro. O segundo fator referese à motivação para que tal valor seja inferior para um público e superior para outro. A hipersexualização da mulher faz com que organizadoras(es) de festas ofereçam ingressos por um preço menor para atrair o público feminino e, como dito na própria discussão dos alunos, essa estratégia serve para os homens terem uma espécie de "vitrine", por meio da qual podem "escolher" com qual das mulheres desejam ficar.

Tal temática gera muita discussão devido à divergência entre o comportamento e o pensamento masculinos, pois, mesmo diante do descontentamento em relação ao pagamento dos ingressos com preços maiores para esse público, os homens ainda frequentam tais festas, pelos motivos apresentados, ligados à objetificação do corpo feminino. O terceiro fator está relacionado ao comportamento exercido por homens e mulheres em festas e retoma a temática apresentada de que as mulheres têm os seus desejos oprimidos, principalmente aqueles relacionados à sexualidade. Isso é ilustrado abaixo por uma aluna que questiona o porquê de mulheres, no exercício de sua sexualidade, ao desejarem ficar com várias(os) mulheres/homens em festas, são hostilizadas, quando o mesmo fato ocorre com homens e não acontece a mesma coisa. 
Por que que mulher que fica com um monte de homem é puta e homem pode ficar com todo mundo que é garanhão? (Nádia, 18 anos, $7^{\circ}$ ano).

Ah, isso aí eu acho errado também. A mina fica com um monte de cara aí é puta, o cara pega um monte ai é foda. (Paulo, 15 anos, $9^{\circ}$ ano).

Em inúmeros relatos, as(os) alunas(os) trouxeram os termos "machismo" e "machista" para explicitar alguma situação ocorrida em suas experiências de vida. Outra questão apresentada em diversas falas das(os) alunas(os) foi o debate em torno de aspectos referentes ao preconceito diante da diversidade de gênero, o qual ainda aparece de forma naturalizada, como indicam os seguintes trechos:

Os homens são mais preconceituosos... tanto quanto ao machismo quanto à escolha sexual. As mulheres aceitam mais se um amigo for gay ou se uma amiga for lésbica, por exemplo... elas aceitam mais ou se for a outra lá... como é o nome? Ah, bissexual também elas aceitam. As mulheres sempre vão aceitar mais. (Geisa, 15 anos, $9^{\circ}$ ano).

Na minha casa os homens só atrapalham! Eles não fazem nada! Isso daí é machismo pra mim. (Carla, 15 anos, $6^{\circ}$ ano).

$E$, eu acho que o homem tem que ser companheiro da mulher, ajudar nas tarefas do dia a dia. Os homens acham que se ajudarem na cozinha vão ser gays. Eu vejo uns homens dizendo assim: "Ah, o homem lá não veio jogar futebol, ficou em casa ajudando a mulher a fazer faxina... É bem puto mesmo! (Cláudio, 21 anos, $8^{\circ}$ ano).

A partir do que foi apresentado, podemos considerar que os movimentos sociais, assim como os papéis de gênero, permeiam o ambiente escolar. Um caso que evidencia a ligação entre os dois assuntos foi a mobilização ocorrida no ano de 2016 no Colégio Anchieta, na cidade de Porto Alegre ${ }^{5}$. Meninas que se sentiam desconfortáveis perante o fato de as autoridades do colégio não permitirem a utilização de shorts ${ }^{6}$ no ambiente escolar manifestaram-se contra tal opressão. O fato teve repercussão nacional e foi intitulado pelas estudantes como "Vai ter shortinho, sim!". Esse tipo de movimento por parte das alunas revela a importância de discussões em torno dessas questões no ambiente escolar e, de algum modo, contribui para que medidas sejam tomadas, ainda que futuramente. Recentemente, foi aprovado na Câmara Municipal de Porto Alegre o projeto de Lei n. 209/17, intitulado Escola Sem Machismo. Nesse documento, são estabelecidas diretrizes norteadoras para que sejam realizadas ações de prevenção e combate à violência contra a mulher e de valorização de meninas e mulheres na rede municipal de ensino (SUL 21, 2018).

\subsection{Papéis de gênero na sociedade}

O tema apresenta os diferentes papéis de gênero existentes na sociedade atual, os quais acabam servindo como base normativa de atitudes consideradas típicas para determinado grupo social e de gênero. Para Cerqueira-Santos (2018), gênero diz respeito à compreensão da construção social do "ser mulher e ser homem" e contrapõe a naturalização pautada no entendimento do sexo biológico como determinante para os papéis sociais. Diversas vezes na

\footnotetext{
${ }^{5}$ Reportagem disponível no link: http://g1.globo.com/rs/rio-grande-do-sul/noticia/2016/02/alunas-fazemmobilizacao-pelo-uso-do-shorts-em-escola-de-porto-alegre.html.

${ }^{6}$ Palavra inglesa para "calção". A princípio, uma calça curta para esportes, de senhora ou de homem, hoje também é usado para outras atividades (DICIONÁRIO INFORMAL, 2009).
} 
sociedade, quando os arranjos culturais naturalizados são questionados no tocante às estruturas generificadas, o estranhamento ocorre. Alguns trechos retirados dos grupos realizados ilustram essa questão:

Vai ficar até meio estranho isso que eu vou falar, mas quando eu era pequeno eu brincava de boneca com a minha irmã e não vejo problema nisso. (Cristiano, 17 anos, $6^{\circ}$ ano).

Eu já vi em algumas famílias comentários do tipo: "Tu não pode jogar futebol porque é coisa de menino, só o teu irmão pode...". Acho ridículo isso. Na minha família graças a Deus nunca teve isso aí. (Douglas, 16 anos, $6^{\circ}$ ano).

Tem a história da cor também, né? Do rosa e do azul. Eu sou mulher e quase nunca uso rosa. (Raíssa, 26 anos, $7^{\circ}$ ano).

Bah, eu uso rosa direto e não tô nem aí. (Milton, 20 anos, $8^{\circ}$ ano).

A partir do exemplo, foi demonstrada a não naturalização do comportamento masculino ao se aproximar de uma brincadeira considerada feminina e infantil. A complexidade da temática não se detém apenas ao que é socialmente aceito para que determinados gêneros possam ou não brincar, mas são essas construções iniciais, desde a possibilidade ou não de um menino usar brincos, até ele usar rosa ou brincar de bonecas, que podem se relacionar a outras questões da vida adulta.

Um dos papéis de gênero ainda estagnados na sociedade, no que tange às mulheres, é o dever da maternidade. Em 1988, o papa João Paulo II divulgou uma carta apostólica em que mencionava que a mulher deveria deter-se à maternidade como seu objetivo principal de vida e que suas funções não deveriam coincidir com objetivos e propósitos masculinos (CONNELL; PEARSE, 2015). Uma das figuras sagradas para o catolicismo, homem e heterossexual, propaga e reproduz discursos generificados e estereotipados, os quais ressaltam e relembram o papel que a boneca tem na vida de uma menina e de uma mulher adulta: a maternidade.

O binarismo de brinquedos e cores designam lugares, espaços e performances de ser e estar no mundo. Os papéis de gênero na sociedade servem como base que dita as atitudes consideradas típicas para determinado grupo social e de gênero (BENTO, 2011). Diversos são os exemplos encontrados no cotidiano, sendo um deles relatado por uma jovem em um dos grupos ao se referir à colocação dos brincos em uma menina logo após seu nascimento, como se fosse algo obrigatório quando se nasce mulher.

A partir dos relatos das(os) jovens, foram percebidas questões de preconceito quando uma jovem que é mãe comenta com as demais colegas do grupo que a escola de seu filho impõe regras quanto ao uso do brinco, alegando que as meninas podem usar porque não fazem atividades mais bruscas, mas os meninos não, porque têm maior possibilidade de se machucarem com o acessório na Educação Física, por exemplo. Pode-se inferir o quanto as instituições escolares reproduzem normas e preconceitos de gênero.

As professoras achavam que não era certo porque os coleguinhas falavam coisas pra ele e daí eu fui lá no colégio, bati o pé e reclamei! 'Independente se ele usar brinco ou não, ou se ele quiser vir de rosa, vocês vão ter que aceitar!'. Normalmente as outras mães só aceitam, mas eu fui lá e não aceitei. (Raíssa, 26 anos, $7^{\circ}$ ano).

E no colégio também teve uma situação assim, porque tava escrito num papelzinho que não podia usar brinco, porque podia se machucar... ai eu disse que não, que tava errado isso aí. Por que uma menina pode usar brinco e ele não pode? Ele gosta! É opção dele! (Raíssa, 26 anos, $7^{\circ}$ ano). 
Se tem uma brincadeira de casinha, as gurias brincam sozinhas. (lago, 17 anos, $7^{\circ}$ ano).

Ah, depende, meu! Tem guri que quando é pequeno interage com guria e tem guria que quando é pequena interage com guri, que quer jogar futebol também, no meio dos guri. (Laércio, 17 anos, $9^{\circ}$ ano).

Não, é estranho. Imagina uma mulher vindo de bunda pra ti, tu vai chegar como? (Wilmar, 16 anos, $7^{\circ}$ ano).

Seu machista! (Beatriz, 29 anos, $6^{\circ}$ ano).

O padrão de normalidade está inserido no princípio de "igualdade", sendo que o sentido ideológico que define o que é ou não "normal" pode diferir entre regiões e contextos históricos. Em termos conceituais, é difícil definir o que é a normalidade. Todavia, é realizada a associação de um conjunto de padrões comportamentais como esses aceitos ou não socialmente para determinados indivíduos (MAIA, 2009). Os homens já discutiam sobre diferentes concepções de gênero a partir de exemplos práticos de como isso implica seus pensamentos, ou seja, mulheres brincam de bonecas para talvez tornarem-se mães, mas os meninos, talvez futuros pais, se brincarem de bonecas, são tomados pela associação a uma brincadeira "de menina".

Nos trechos a seguir, aparecem novamente as concepções e os papéis de gênero como sendo uma consequência das ações e dos discursos reproduzidos pelo grupo, porém com um viés de criticidade no tocante a esses pré-conceitos.

O preconceito que a escola tem é muito mais dos homens do que das mulheres, os homens são mais machistas. Por exemplo, o nosso colega disse que o meu marido era bem veado e que eu ia levar um chifre.... Os homens são muito machistas quando o assunto é sexualidade. (Raíssa, 26 anos, $7^{\circ}$ ano).

Eles acham que toda feminista é uma mulher macho. (Vitor, 17 anos, $7^{\circ}$ ano).

O preconceito em relação ao feminismo, seguido da desinformação sobre o movimento, é grande, visto que feministas são chamadas de lésbicas, diversas vezes, por defenderem a igualdade entre os gêneros, como se uma mulher heterossexual ou bissexual não pudesse lutar por igualdade da mesma forma. No grupo feminino, percebe-se o quanto as mulheres desenvolvem mais o tema, expõem-se mais quanto às suas concepções de feminismos e machismos, trazendo exemplos de experiências pessoais que vivenciaram, e não se intimidam ao relatar que já sofreram inúmeras opressões. Em relação a um dos grupos mistos, os homens fizeram mais afirmações criticando o machismo do que as mulheres no grupo em que estavam sozinhas, pois houve discursos femininos defendendo posturas machistas, demonstrando como não há uma relação direta entre gênero e políticas de igualdade de gênero.

A escola pode ser situada como um espaço de ambiguidades no que se refere às questões de gênero, pois se, por um lado, seus dispositivos pedagógicos (re)produzem normatividades quanto aos papéis masculinos e femininos, por outro, novas construções e experiências estão sendo construídas, e nelas atitudes de resistência ganham corpo. Assim, foi possível perceber a facilidade com que o ambiente escolar tende a reproduzir papéis de gênero. Tal fenômeno pode ocorrer no Ensino Fundamental, como no caso do colégio que não aceitou que a mãe de um dos alunos tenha colocado brincos nas suas orelhas e, ainda, no caso da separação de brincadeiras como sendo "de menina" ou "de menino". Ademais, as situações podem também ocorrer independentemente do período escolar; a puberdade é latente, e as questões envolvendo 
os papéis de gênero são mais evidentes. Ainda assim, a escola muitas vezes parte para um viés biológico - e não social - no ensino da sexualidade. Nesse sentido, as(os) estudantes da EJA, público pesquisado neste estudo, também trouxeram vivências e relatos acerca da falta de discussões em torno de temáticas como gênero e sexualidade no ambiente escolar.

Por maiores que sejam as consequências de não serem discutidas no ambiente escolar algumas temáticas cruciais para o desenvolvimento humano, é ainda apresentada resistência para o debate sobre o tema. Segundo Gomes (2013), a Educação é sempre uma ação política; portanto, o gênero e a educação sexual devem fazer parte do currículo escolar desde a infância. A escola deve, igualmente, respeitar a diversidade humana presente na sociedade e transcender as esferas de um ensino sistemático para que o preconceito e a discriminação sejam colocados de lado.

\section{CONSIDERAÇÕES FINAIS}

De que forma as construções de gênero são realizadas e percebidas pelo olhar das(os) jovens em suas vivências diárias? Esse questionamento delineou a intenção inicial do estudo Todo mundo é igual? Construções de gênero sob o olhar da juventude. A partir da investigação, as percepções das(os) alunas(os) foram divididas em dois temas de análise. Os resultados apontam para o modo como as(os) jovens percebem as mesmas questões de formas distintas, até mesmo em função de terem vivências diferentes de vida, o que para Bock (2007) são características evidentes entre grupos de diferentes classes sociais, devido às diferentes formas de inserção social dessas pessoas durante suas vidas.

Diversas percepções acerca das questões de gênero fizeram-se presentes, demonstrando como as(os) jovens constroem significados, tanto a partir de conteúdos propagados pela mídia quanto por meio de informações compartilhadas em suas redes pessoais ou no ambiente escolar, revelando como essas construções de gênero apresentam-se de forma plural para as(os) jovens na sociedade atual. O preconceito e a ignorância acerca do assunto se dão também em decorrência da falta de informação e debates em torno dessas temáticas. Desse modo, não se trata apenas de estabelecer o diálogo, mas de modificar estruturas capazes de produzir desigualdade e injustiça nas questões de gênero e sexualidade (SEFFNER; PICCHETTI, 2016).

O cuidado para que as opiniões pessoais das(os) autoras(es) não interferissem nos relatos das(os) participantes e para que as percepções das(os) alunas(os) viessem única e exclusivamente delas(es) foi uma das dificuldades encontradas no decorrer do processo, já que, em diversos momentos, até para fins de mediação da discussão, as(os) autoras(es), amparados pelo conceito de campo-tema apresentado por Spink (2003), sentiram a necessidade de instigar um pensamento mais crítico do que aquele que estava se delineando. Foi desafiador e ao mesmo tempo uma das limitações da pesquisa não se envolver diretamente com algumas afirmações das(os) alunas(os), pois aquelas percepções, principalmente em discursos carregados de preconceito e desinformação, apareceram de acordo com as experiências de vida que elas(es) vivenciaram e que são diferentes das experiências de vida das(os) autoras(es).

Outra dificuldade encontrada durante a pesquisa foi a diferença de pensamento entre as(os) profissionais da escola, visto que o nível de importância que umas(uns) davam para a realização dos grupos demonstrava o quanto algumas(uns) professoras(es) ainda mantêm um pensamento naturalizado acerca das questões de gênero. A formação das(os) professoras(es) é fundamental, pois ela ainda é praticamente inexistente ou até mesmo equivocada no que concerne às questões 
de gênero. Ainda é, muitas vezes, guiada por princípios e valores pessoais, religiosos, entre outros, os quais não partem de um conhecimento científico (FERREIRA; SANTOS; QUADRADO, 2017). É necessário que a escola reflita qual sua função em relação às(aos) alunas(os) que se sentem discriminadas(os) e excluídas(os) na escola. Todavia, por mais que existam resistências por parte de algumas(uns), aquelas(es) que se interessam e demonstram seu apoio à inserção desses conteúdos em sala de aula compensam a falta daquelas(es) que não acreditam no trabalho realizado, visto que em mais de um momento algumas(uns) professoras(es) procuraram a mestranda para convidá-la a propor um grupo de discussão com elas(es), a fim de também usufruírem do momento rico de discussão que as(os) alunas(os) estavam tendo.

O presente estudo contribui para a análise das relações de gênero no contexto escolar e para a fundamentação de possíveis políticas públicas acerca dessa temática. $O$ artigo compõe o cenário apresentando também apontamentos para a Educação. As juventudes são um grupo complexo e bastante conectado às mudanças sociais, inclusive pensando o contexto das mídias sociais e dos saberes produzidos pela educação. O ensino de jovens e adultos no Brasil é atravessado por um severo quadro de desigualdades e percursos pouco lineares na vida escolar. Uma amostra como essa evidencia não somente uma comunidade escolar, como também exibe um recorte de classe muitas vezes de difícil acesso. Torna-se fundamental que as(os) jovens aprendam a refletir, criticar, agir com responsabilidade e enfrentar os problemas que possam surgir (RAFAELI, 2015). Assim, outros estudos devem ser realizados objetivando ampliar o debate e contribuindo para o avanço de pesquisas sobre o tema, de forma a possibilitar que jovens estudantes de demais modalidades de ensino conectem-se com o mundo dispondo de uma educação transformadora.

\section{REFERÊNCIAS}

ASSUNÇÃO, Raquel Sofia; MATOS, Paula Mena. Perspectivas dos adolescentes sobre o uso do Facebook: um estudo qualitativo. Psicologia em Estudo, Maringá, v. 19, n. 3, p. 539-47, 2014.

BACKES, Dirce Stein; COLOMÉ, Juliana Silveira; ERDMANN, Rolf Herdmann; LUNARDI, Valéria Lerch. Grupo focal como técnica de coleta e análise de dados em pesquisas qualitativas. O mundo da saúde, São Paulo, v. 35, n. 4 , p. $438-42,2011$.

BARBOUR, Rosaline. Grupos focais. Porto Alegre: Artmed, 2009.

BENTO, Berenice. Na escola se aprende que a diferença faz a diferença. Revista Estudos Feministas, Florianópolis, v. 19, n. 2, p. 549, jan. 2011.

BERNARDES, Márcia. Uma reflexão inicial sobre feminismo na internet: gênero e corpo. In: CONGRESSO INTERNACIONAL COMUNICAÇÃO E CONSUMO. 7 de outubro, São Paulo. Anais [...]. São Paulo: COMUNICON, 2014.

BOCK, Ana Mercês Bahia. A adolescência como construção social: estudo sobre livros destinados a pais e educadores. Psicologia Escolar e Educacional, Campinas, v. 11, n. 1, p. 63-76, jun. 2007.

BRASIL. Lei 12.852, de 5 de agosto de 2013. Estatuto da Juventude. Brasília, 2013.

BRAUN, Virginia; CLARKE, Victoria. About thematic analysis. The University of Auckland website, 2006.

CAMPOS, Luciana Maria Lunardi. Gênero e diversidade sexual na escola: a urgência da reconstrução de sentidos e de práticas. Ciência \& Educação, Bauru, v. 21, n. 4, p. I-IV, dez. 2015. 
CERQUEIRA-SANTOS, Elder. Sexualidade na adultez emergente: gênero, orientação sexual e identidade. In: DUTRA-THOMÉ, Luciana; PEREIRA, Anderson Siqueira; NUÑES, Susana; KOLLER, Silvia Helena (Org.). Adultez emergente no Brasil: uma nova perspectiva desenvolvimental sobre a transição para a vida adulta. São Paulo: Vetor, 2018.

COELHO, Mayara Pacheco. Vozes que ecoam: feminismo e mídias sociais. Pesquisas e Práticas Psicossociais, São João del-Rei, v. 11, n. 1, p. 214-24, jun. 2016.

CONNELL, Raewyn; PEARSE, Rebecca. Gênero: uma perspectiva global. São Paulo: Versos, 2015.

DICIONÁRIO INFORMAL. Definição do termo "shorts". 2009. [Definição publicada na página do Dicionário Informal].

FERREIRA, Ewerton da Silva; SANTOS, Oneide Alessandro Silva dos; QUADRADO, Jaqueline Carvalho. Gênero e diversidade na escola: experiências sobre a formação continuada de professores da educação básica no município de São Borja-RS. Revista sociais \& humanas, Rio Grande do Sul, v. 30, n 2. p. 237-49, abr/ago 2017.

GASKELL, George. Entrevistas individuais e grupais. In: BAUER, Martin; GASKELL, George (Org.), Pesquisa qualitativa com texto, imagem e som: um manual prático. Petrópolis, RJ: Vozes, 2002. p. 64-89.

GOMES, Andréa Regina de Carvalho. Gênero e sexualidade na escola. In: CONGRESSO DE EDUCAÇÃO, 11., 24 de setembro, Curitiba. Anais [...]. Curitiba: PUC Paraná, 2013.

JUNQUEIRA, Rogério Diniz. Pedagogia do armário: a normatividade em ação. Retratos da Escola, Brasília, v. 7, n. 13, p. 481-98, 2013.

LÉVY, Pierre. O que é o virtual? São Paulo: Editora 34, 1999.

MAIA, Ana Cláudia Bortolozzi. Sexualidade, deficiência e gênero: reflexões sobre padrões definidores de normalidade. In: JUNQUEIRA, Rogério Diniz (Org.). Diversidade sexual na educação: problematizações sobre a homofobia nas escolas. Brasília: UNESCO, 2009. p. 265-291.

MISKOLCI, Richard. Teoria Queer: um aprendizado pelas diferenças. Belo Horizonte: Autêntica Editora/ UFPO, 2012. (Cadernos da Diversidade).

NUNES, Brasilmar Ferreira; WELLER, Wivian. A juventude no contexto social contemporâneo. Estudos de Sociologia, [s. I.], v. 2, n. 9, p. 43-57, abr. 2014.

PIZZINATO, Adolfo; PETRACCO, Milene Mabilde; HAMANN, Cristiano; CÉ, João Pedro; ROSA, Eduarda Noal. Juventude feminina do meio rural: sentidos sobre educação e perspectivas sobre futuro. Psicologia Escolar e Educacional, Paraná, v. 21, n. 1, p. 41-51, 2017.

PORTAL EDUCAÇÃO. Educação de Jovens e Adultos. Portal Educação, 2017.

RAFAELI, Rosângela Aparecida Soares Tristão. Educação de Jovens e Adultos: aspectos históricos e sociais, com uma breve abordagem sobre Tecnologia Educacional. Repositório de artigos do Instituto Federal de Santa Catarina, Florianópolis, 31 de outubro, 2015.

RIZZA, Juliana Lapa; RIBEIRO, Paula Regina Costa; MOTA, Maria Renata Alonso. A sexualidade nos cursos de licenciatura e a interface com políticas de formação de professores/as. Educação e Pesquisa, São Paulo, v. 44, e176870, p. 1-18, 2018. 
SCOTT, Joan. Gênero: uma categoria útil de análise histórica. Educação e Realidade, Cidade, v. 20, n. 2, p. 71-99, 1995.

SEFFNER, Fernando. Atravessamentos de gênero, sexualidade e educação: tempos difíceis e novas arenas políticas. Trabalho encomendado para a Reunião Científica Regional da ANPED. Curitiba: UFPR, 2016.

SEFFNER, Fernando; PICCHETTI, Yara de Paula. A quem tudo quer saber, nada se lhe diz: uma educação sem gênero e sem sexualidade é desejável? Reflexão e ação, Santa Cruz do Sul, v. 24, n. 1, p. 61-81, abr, 2016.

SPINK, Peter Kevin. Pesquisa de campo em psicologia social: uma perspectiva pós-construcionista. Psicologia \& Sociedade, Porto Alegre, v. 15, n. 2, p. 18-42, dec. 2003.

SUL 21. Redação do Jornal. Câmara de Porto Alegre aprova projeto de 'Escola sem Machismo'. Sul 21, 29 de novembro, 2018.

THOMPSON, John Brookshire. Ideologia e cultura moderna: teoria social crítica na era dos meios de comunicação de massa. Petrópolis, RJ: Vozes, 2007.

WOITOWICZ, Karina Janz. Imprensa feminista no contexto das lutas das mulheres: Ativismo midiático, cidadania e novas formas de resistência. Revista Ação midiática - Estudos em Comunicação, Sociedade e Cultura, da Universidade Federal do Paraná, Curitiba, v. 2, n. 1, p. 1-18, 2012.

\section{Sobre os autores:}

Caroline Gonçalves Nascimento: Doutoranda e mestra em Psicologia pela Pontifícia Universidade Católica do Rio Grande do Sul (PUCRS). Psicóloga pela Universidade La Salle. Integrante do Grupo de Pesquisa Preconceito, Vulnerabilidade e Processos Psicossociais (PVPP/PUCRS). E-mail: carolineegn@gmail.com, Orcid: http://orcid.org/0000-0003-4789-9474

Millena Holz Waskow: Graduanda em Psicologia na Universidade Federal de Ciências da Saúde de Porto Alegre (UFCSPA). Colaboradora do Grupo de Pesquisa Preconceito, Vulnerabilidade e Processos Psicossociais (PVPP/PUCRS). E-mail: millenaholzwaskow@gmail.com, Orcid: http://orcid.org/0000-0001-8707-6187

Marlene Neves Strey: Doutora em Psicologia pela Universidad Autónoma de Madrid. Psicóloga pela Pontifícia Universidade Católica do Rio Grande do Sul (PUCRS). Professora do Mestrado Acadêmico em Psicologia na Universidade Feevale. E-mail: nevesstrey@gmail.com, Orcid: http://orcid.org/0000-0003-3030-5668

Ângelo Brandelli Costa: Doutor em Psicologia e psicólogo pela Universidade Federal do Rio Grande do Sul (UFRGS). Professor do Programa de Pós-Graduação em Psicologia na Pontifícia Universidade Católica do Rio Grande do Sul (PUCRS). Coordenador do Grupo de Pesquisa Preconceito, Vulnerabilidade e Processos Psicossociais (PVPP/PUCRS) e conselheiro titular do Conselho Regional de Psicologia do Rio Grande do Sul (CRPRS). E-mail: angelobrandellicosta@gmail.com, Orcid: http://orcid.org/0000-0002-0742-8152 